\title{
Reflections on Active Teaching and Learning of Research Methodology from Undergraduates' and Instructor's Perspectives
}

\author{
Mohammed Abdullah Alharbi ${ }^{1}$, \& Abdulrahman Alqefari ${ }^{2}$ \\ ${ }^{1}$ Department of English, College of Education, Majmaah University, Majmaah, Saudi Arabia \\ ${ }^{2}$ Department of English, College of Education, Majmaah University, Zulfi, Saudi Arabia \\ Correspondence: Mohammed Abdullah Alharbi, Department of English, College of Education, Majmaah University, \\ Majmaah, Saudi Arabia.
}

Received: July 15, 2021

Accepted: August 6, $2021 \quad$ Online Published: August 11, 2021

doi:10.5430/wjel.v11n2p84

URL: https://doi.org/10.5430/wjel.v11n2p84

\begin{abstract}
Research methodology courses are challenging for students and instructors. They demand students and teachers to master abstract knowledge of the content. Therefore, the present study attempted to shed light on active teaching and learning — an instructional approach that engages learners in interactions and reflection on learning - of research methodology from the perspectives of undergraduates and the course instructor at Majmaah university. Classroom observations and follow-up interviews with 14 undergraduate students and the course instructor were conducted to achieve this. While the participants highlighted some benefits (learning about research methods, enhancing their assignments, raising their interests in research methodology, learning through group work, and discussions and feeling satisfied and self-confident), they also faced several challenges (content-related challenges, task-related challenges, and active learning-related challenges). Thus, the study offers useful theoretical and pedagogical implications for instructors and future research on circumventing challenging issues in such courses.
\end{abstract}

Keywords: research methodology, active learning, research challenges, evaluation of learning, teaching methodology

\section{Introduction}

Previous research has highlighted the challenging nature of research methodology teaching and learning (Earley, 2014). Such challenges both students and instructors faced include difficulty understanding abstract concepts in research method courses, difficulty involved in simplifying the subject matter/content of these courses and making it relevant to students' tasks and assignments, and students' negative attitudes towards learning, as well as their feeling of the irrelevance of such courses to their learning, anxiety, and fears (Lundahl, 2008; Earley, 2014; Howard \& Brady, 2015). Such courses are even challenging for instructors, especially those novice instructors who do not have sufficient experience in teaching research methodology (Crooks et al., 2010; Hesse-Biber, 2015; Murad \& Al Qunayeer, 2020; Nind \& Lewthwaite, 2018). These researchers pointed out several challenging issues instructors faced in teaching such courses related to their prior research methodology knowledge and experience in teaching such courses, their confidence, and how to deal with student-related challenges.

Studies have reported the implementation of diverse tasks and activities in such courses taken by undergraduates and postgraduates in different disciplines (e.g., Benson \& Blackman, 2003; Lundahl, 2008; Vandiver \& Walsh, 2010; Keenan \& Fontaine, 2012; Roman \& Uttamchandani, 2018;), owing to the challenging and daunting nature of research methodology teaching and learning. These tasks and activities, such as engaging students in developing research projects and proposals through peer feedback, group discussions, or seminars, and even instructional feedback, are founded on the active learning approach. Pedagogically defined, active learning is an approach that engages learners in activities and practices that promote their interactions and reflection on learning (Benson \& Blackman, 2003). It is also known as an instructional approach that has been used in different courses and different disciplines (Drew \& Mackie, 2011; Roman \& Uttamchandani, 2018). As a result of engaging students in active teaching and learning tasks and activities, students have been reported to learn research methodology better (e.g., Barraket, 2005; Ball \& Pelco, 2006), refine and enhance the quality of their research method-related tasks (e.g., Braguglia \& Jackson, 2012; Engbers, 2016; Murad et al., 2020), and increase their interests in research methodology learning as well as feel its relevance to their research tasks (e.g., Edwards \& Thatcher, 2004; Barraket, 2005). 
Despite the evidence that much attention has been paid to research methodology teaching and learning in various domains, research methodology teaching and learning practices have not been sufficiently explored. Researchers have pointed to this gap in research methodology courses, especially in the social sciences (Lombard \& Kloppers, 2015; Nind et al., 2015; Engbers, 2016; Gunn, 2017;). This motivated us to conduct the current study on exploring the research methodology learning opportunities afforded and challenging concerns arising from active teaching and learning in an undergraduate course from the perspectives of students and the course instructor.

\section{Literature Review}

\subsection{Theoretical Perspectives}

Active learning is defined as an approach that centers on the active involvement of learners in learning. Unlike instructional approaches that focus on the didactic manner of transmitting knowledge, the active approach focuses on engaging learners in activities and practices that allow them to acquire knowledge and experience (Keyser, 2000; Kilburn et al., 2014). The active learning approach is also regarded in some earlier studies as a theoretical learning approach (Kilburn et al., 2014). The approach has also been used in other studies on research methodology courses as a student-centered approach because it is intended to engage learners in activities and research-related tasks that promote their role from being a mere passive receiver of knowledge to an active constructor of knowledge (Edwards \& Thatcher, 2004; Lundahl, 2008; Vandiver \& Walsh, 2010; Keenan \& Fontaine, 2012).

\subsection{Opportunities for Research Method Learning Through Active Teaching}

Due to the challenging nature of research method teaching and learning, instructors, educators, and scholars have implemented various tasks and activities founded on the active learning and sociocultural approach. For the tasks, most studies have reported assigning students to research projects that need to be constructed by students either in groups or individually (e.g., Ball \& Pelco, 2006; Lundahl, 2008; Vandiver \& Walsh, 2010; Braguglia \& Jackson, 2012; Keenan \& Fontaine, 2012). Other studies have also reported implementing research proposal tasks (e.g., Benson \& Blackman, 2003; Edwards \& Thatcher, 2004) and even critical reports of previous research on specific topics (e.g., Howard \& Brady, 2015). Some other activities implemented in research method teaching and learning are peer feedback (Benson \& Blackman, 2003; Keenan \& Fontaine, 2012), group discussions (Keenan \& Fontaine, 2012; Jakeman et al., 2017), and even peer review (Vandiver \& Walsh, 2010; Braguglia \& Jackson, 2012; Keenan \& Fontaine, 2012).

The above studies indicate that research projects and proposals engage students in active learning through several steps: topic selection, problem identification/construction, literature review writing, and development of their research instruments. For instance, Saeed and Al Qunayeer (2020) revealed that the engagement of postgraduates in active learning through research proposals created opportunities for students to receive instructional feedback and peer feedback and motivated them to go through several drafts of their tasks. Similarly, in another recent study (Saeed et al., 2020), research proposal tasks integrated into a postgraduate research methodology course allowed the students to apply what they learned to their proposals (e.g., reviewing the literature, stating their problems, and designing their methods). However, projects also involved students collecting the data, analyzing the data, and interpreting and reporting the findings. Moreover, such active learning tasks and activities afford learners the opportunities for better research method learning (; Edwards \& Thatcher, 2004; Barraket, 2005; Ball \& Pelco, 2006; Vandiver \& Walsh, 2010), revising and enhancing their method-related research tasks (Braguglia \& Jackson, 2012; Keenan \& Fontaine, 2012; Engbers, 2016; Jakeman et al., 2017). Such tasks and activities also offer students the chance to link their learning to the assignments (Benson \& Blackman, 2003; Edwards \& Thatcher, 2004). Other better learning opportunities are implicated by students' development of self-confidence (Barraket, 2005; Jakeman et al., 2017), critical reflection on their learning (Benson \& Blackman, 2003), and decision-making skills as implicated by their choices of methods in their tasks (Engbers, 2016). As a result of this, learners see the relevance of research method courses to their learning (Engbers, 2016) and become more interested in and appreciative of research method learning (Edwards \& Thatcher, 2004; Barraket, 2005; Ball \& Pelco, 2006; Lundahl, 2008).

\subsection{Challenges in Research Methodology Courses}

Despite the above encouraging research methodology learning opportunities provided by implementing various tasks and activities to students in research methodology courses, several challenges and concerns arise from research methodology teaching and learning. Studies focusing on the implementation of active teaching and learning in such courses reported that students and instructors are challenged by the complex nature of the content knowledge of the course itself (Keenan \& Fontaine, 2012), the effort and hard work demanded and the time-consuming nature of doing research/research projects (Lundahl, 2008), the time allocated for the course (Lundahl, 2008; Coronel Llamas \& 
Boza, 2011; Keenan \& Fontaine, 2012; Engbers, 2016), and the large number of students and the large number of student groups (Engbers, 2016). Other challenges identified by Saeed and Al Qunayeer (2020) are (a) those related to the subject matter (e.g., difficulty in successfully selecting and applying research designs to research proposal tasks), (b) those related to students themselves (e.g., pre-assumption and anxiety about the course), and (c) those related to instructors (e.g., being challenged by the content knowledge of the course).

A heavy workload outside the regular class time is assigned to students and sometimes instructors; therefore, much pressure/stress is placed on students and instructors (Ball \& Pelco, 2006; Lundahl, 2008). As a result, opportunities for better learning of research methodology through peer/group discussions and review (Jakeman et al., 2017), as well as practical research-related activities (Coronel Llamas \& Boza, 2011), are restricted or minimized, and students' successful accomplishment of research-related tasks, especially research projects, are hindered (Lundahl, 2008). Additionally, in research methodology courses where research projects are assigned to groups, information is provided poorly without engaging students in active learning (Coronel Llamas \& Boza, 2011).

The above literature on the opportunities and challenging issues in research methodology courses has enriched our understanding of the role of active learning strategies and practices in fostering learning about research methodology among postgraduates and undergraduates. Yet, most of the above studies have focused either on students' perspectives or instructors' perspectives. This suggests the need for approaching such an interesting research topic from reflections of both students and course instructors on active teaching and learning of research methodology. Therefore, the present study attempted to answer the following research questions:

1) What are the major opportunities for research methodology learning afforded by active teaching and learning to undergraduate students?

2) What are the main challenging concerns emerging from active teaching and learning practices in the undergraduate course?

\section{Method}

\subsection{Research Design}

The present study used a reflective case study based on a qualitative research approach that sought to understand how people engaged in particular practices reflect upon these practices (Barraket, 2005). In this study, the reflective case study approach seemed suitable for exploring a group of participants' reflections on their own practice in a particular setting (Leshem \& Trafford, 2006). Furthermore, in using this approach, the researcher could obtain rich data on how the teaching and learning of this particular research method were experienced or how participants joining the course reflect on their own experience in teaching and learning research methods.

\subsection{Study Setting}

This study was conducted on an undergraduate research methodology course in education taught to 14 undergraduates and the course instructor at Majmaah university. The participating students were all male undergraduates joining the sixth level in the Bachelor's Degree program at the facility. A case can be an individual person or a particular group, or even an organization (Schoch, 2016). In this study using a case study approach, the course was selected as a particular case study in a teaching and learning context with its defined space and time frame (Seawright \& Gerring, 2008; Schoch, 2016). Therefore, all learners joining the course were selected as case subjects regardless of any particular selection criterion. The instructor of the course was also a male lecturer holding a Ph.D. in English Education. His interests are research methodology teaching and learning as part of English teaching and learning. The study was conducted over a semester (4 months) of academic year 2017-2018, a period during which the research methodology course was taught. Our selection of this as the case of our study was due to the importance of this course, which aims to teach research methodology to undergraduates, and easy access to the classroom setting. In other words, since one colleague taught the course, it was easy to access the classroom setting for collecting the data and making observations on teaching and learning practices.

\subsection{Description of the Research Methodology Course}

The course is an introduction to the research methodology, which covers various topics on the different research designs - quantitative, qualitative, and mixed methods research designs. Hence, the course was designed based on recent scholars and researchers (e.g., Tashakkori \& Teddlie, 2003), emphasizing the integrated and complementary relationships between quantitative and qualitative research approaches and Creswell's (2013) textbook on the mixed methods research approach. The course also included several lectures on research proposal writing-topic selection, problem formulation, research objectives, and research questions, and literature review writing. 
The students were evaluated through two main tasks - critical report writing and research proposal. The critical report writing task focused on selecting three research articles on a specific topic on English language learning and teaching. The students were required to read the three articles, summarize them, compare them, and highlight the strengths and weaknesses concerning the objectives, questions, theories used, literature reviews of previous research cited in the articles, and the methods employed and findings obtained. The students were to accomplish this task in small groups or pairs, so they were divided into seven pairs. The research proposal task assigned to individual students aimed at enabling the undergraduates to plan a study on a particular topic of interest in the same discipline of English language learning in the form of a three-chapter proposal-Introduction, Literature Review, and Methods. Each individual student had to select a research topic and start planning the proposal from the title formulation to the research method.

\subsection{Active Teaching and Learning Activities}

The active teaching and learning activities applied in the research methodology course and observed by the researcher centered around (a) engaging the undergraduates in individual and pair work through a gradual and staged process of doing the assigned tasks from the early stage, (b) monthly classroom seminars, and (c) weekly online teacher and peer feedback sessions. For the first activity, the students were observed to start doing the tasks almost from the third week of the semester. They went through a gradual process of doing both tasks, which appeared to be staged according to what the instructor taught in the course. For instance, for the proposal, they started reading about a topic; they then formulated their titles during the third week after they had been taught the structure of a research proposal and how it should be done. So, in brief, while the students engaged in pair work on doing their critical reports, they were also involved in individual work on the research proposals. In both tasks, the students were asked to write their assignments using Google Docs pages. The instructor shared with each pair of students for critical report writing and individual students for research proposal writing.

Another teaching and learning activity used once each month was the classroom seminar. Each month, a classroom seminar was held, which lasted 3 hours. In each seminar, the students were asked to present their individual and paired work progress (5-7 minutes for each presentation). As each student presented work progress, the instructor and other students were observed taking notes on the presenter's progress. Then, after each presentation, the instructor asked the other peers to provide feedback on the presenter's progress by pointing to the issues, providing suggestions, and asking questions. Following peers' comments, the instructor commented on the presenter. The presenter was also allowed to reply to comments or answer peers' and the instructor's questions. Each seminar was observed to cover all students' presentations of their progress on both tasks.

A final activity observed after the fourth week was that the researcher was added to the course WhatsApp group and invited to join the Google Docs pages for online teacher and peer feedback. In this regard, the instructor was observed to initiate online discussions with the students in the WhatsApp group beyond the classroom time. They usually discussed issues they encountered in executing the tasks and were allowed to ask the instructor questions related to the tasks. The instructor appeared to be responsive to students' concerns and questions by replying to them through written messages and even voice messages. The instructor also engaged the students deeply in research methodology learning by guiding them, reading their tasks, commenting on them, and through the Google Docs commenting facility. The students were also observed to respond to the instructor's comments or feedback by revising their drafts using the Google Docs track change facility that the instructor could trace.

\subsection{Data Collection}

Before collecting the data, the researcher contacted the course instructor and explained the purpose of this research. The students were also informed of our data collection. They were also informed that the information would be confidential. Based on this, they signed the written consent for their participation.

The data were collected through classroom observations and follow-up semi-structured interviews. The researcher attended the weekly research methodology classes. He stayed at the back of the class, observing what was occurring and taking notes on the classroom activities framed within the active learning approach and challenges in research methodology learning either expressed by students through their interactions with the instructor in the class or articulated by the instructor himself as part of his lectures delivered to the students. This allowed the researcher in part to construct the questions for the follow-up interviews.

The follow-up semi-structured interviews were conducted during the last 2 weeks of the semester. Before the interview sessions, the researcher designed the questions based on previous research and classroom observations (see Appendix). Additionally, some other questions seeking justifications or clarifications from the students and instructor 
were also asked during the interviews. The interviews were conducted individually, with each session taking almost 10-15 minutes. The researcher recorded each session using his mobile audio recorder. Then, he started interviewing the students, and finally, he interviewed the instructor, as some responses given by the students needed the instructor's reflections on them.

\subsection{Data Analysis}

The study used thematic analysis of the data collected. The observation notes were compiled and organized in separate word files. The follow-up interviews were listened to, transcribed, and later read carefully, along with the notes. In carrying out the thematic analysis of the observation notes, the notes were read, and themes related to the observed challenging issues in teaching and learning research methodology were identified according to the research questions. We also used the structure of research proposals and components provided to the students at the start of the semester to categorize the themes or challenging issues addressed by the lecturers through the feedback noted during the semester. Later, we also sought evidence on these challenges from the follow-up interviews.

The interviews were also read carefully, and the transcripts were coded according to the issues and challenges emerging from the observation while allowing for more emerging themes from the data. Then the interviews were coded in terms of the learning opportunities provided to the learners in research methodology. Regarding this, our analysis was mainly based on the literature review of previous research. Identifying themes from the data was iterative. It involved the researcher and another research assistant coding and re-coding, comparing the themes, and discussing their agreements and disagreements on some themes. Finally, the main themes and subthemes identified from the data were summarized, interpreted, and represented by segments extracted from the follow-up interviews. To maintain an objective and reliable data analysis, the researcher and another assistant were involved in coding and discussing the data. They also had several meetings to resolve inconsistency and disagreements until reaching a rate of almost $94.5 \%$ agreement on all codes and themes.

\section{Findings}

\subsection{Learning Opportunities}

The findings obtained from our observations and students' and the instructor's reflections on their active teaching and learning of the research method course revealed that such an active approach afforded the students several opportunities for better learning, which are discussed in the following subthemes.

\subsubsection{Learning About Research Methods}

Over time, we observed that the students became better at learning about research methods from the course as implicated through their presentations and online discussions. In comparison to the first few weeks, the seminars conducted before the end of the semester showed that most of the students exchanged feedback on their presentations of proposals, which showed their understanding of what they learned in the course. In the follow-up interviews, the students expressed their views on the better research method learning opportunities afforded by the course: "I am glad I learn[ed] a lot of things already about the different research methods" (S8). Other students also talked about learning some research-related skills, such as how to do research proposals: "This course helped us to get the whole picture of how to do a research proposal" (S5).

What was of importance for better learning about research methods is not the mere knowledge acquired by the students, but also the opportunities for linking or relating what they learned in the course to their research proposals: "The most interesting part of the course is that the research methodology as the lecturer explained everything and gave explanations and examples related to our proposals. So, I understood the lectures, and I could apply what he has taught us" (S10). The instructor also referred to this important learning outcome by stating: "We do not assume students would learn everything about research methods over one semester, but at least they finish the course while they have acquired basic knowledge that helps them in doing their proposals" (Instructor).

\subsubsection{An Opportunity to Enhance Their Tasks}

Based on our observations of the instructor's comments on the final drafts of tasks presented by the students in the final seminar, the students appeared to have fixed most of the issues and flaws in their drafts. The comments were also observed to praise students for enhancing their drafts, particularly their research proposals. Their voices in the interviews indicate that most of the students found adequate opportunities to refine their drafts and improve them: "So that was really good for me. Then, after receiving the revised drafts, I really felt satisfied about them" (S4). They also perceived improvements of specific areas in their final drafts, including writing and content: "So it actually helped me a lot to improve my writing - to include more into the contents of my writing" (S7). 
The instructor was also asked to give his initial evaluation of the final drafts in the interviews. His responses indicated that although he had not marked the final drafts of the tasks, he could observe improvements made by the students to their final drafts: "I would say yes the students were able to improve their tasks when you compare the final drafts and initial drafts." He also talked about initially observed important areas of improvements in students' tasks: "Yup, I could observe from their final presentations and also written drafts submitted to the course spectrum improvements to content, also methods and literature reviews of their proposals."

\subsubsection{Creating Interests About Research Methodology Learning}

The students talked about their interests in research methodology learning through group work and discussions. Most of them described their group work on the critical reports as one of the factors contributing to developing their interests in learning. As each of the three students engaged in collaboratively developing their critical reports of four papers or research articles on a particular topic of their interests, they could divide their tasks, plan their reports, and contribute tasks: "The group work made our learning of research methods interesting as it really helped us to look out for each other, care for each other, equally contributing to the assignments and doing well as a group" (S9). Some students also appreciated the peer support exchanges on their reports for they could learn from each other: "As I told before it was my first semester, so group study helps me to learn more and share our knowledge regarding our topics" (S1).

The students also valued the monthly seminars during which they presented their progress and discussed the issues. Some of them valued the peer and instructor's feedback and comments on their presentations: "Apart from the lecturer's feedback, peer feedback was also interesting because it helped me to get new perspectives from my peers" (S3). They added the discussions in the monthly seminars helped them to re-look at the presentations from peers' eyes: "I prefer group discussions because in group we used to discuss, learn from each other and see our issues through others" (S6).

\subsubsection{Feeling Satisfied and Self-Confident}

The final learning outcomes of active teaching and learning of research methodology perceived by the students are related to their satisfaction and developing self-confidence during the semester. All the students interviewed expressed their satisfaction about their learning in this course for the course met what they expected when they joined the course: "I am satisfied that the course met my expectation which is how to write a good research proposal with citation, which I had no idea about it before" (S8).

Most of the students also perceived the role of such active teaching and learning activities in developing their self-confidence. They compared themselves after finishing the course to the initial stage when they joined the course and started working on their assignments: "I was not confident to write about the tasks at first, but now I can say I am confident" (S3). Some of them referred to their becoming self-confident as a result of the instructor's and peer support: "I felt self-confident because of the help given by my lecturer and friends" (S10). On the other hand, a few of them did not seem to be confident enough, even after taking the course: "I would say confident, but not very confident, yeah. I still need some guidance, too" (S4).

\subsection{Challenging Concerns}

Based on our findings, despite the above-perceived learning opportunities, there are several challenging issues the case instructor and students faced that center around three main themes: course/subject matter, task, and active teaching and learning.

\subsubsection{Content-Oriented Challenging Issues}

Our observations and follow-up interviews indicate that the students and instructor encountered several challenges related to the course content. The first challenging issue was understanding and applying some of what was learned and taught in the assigned tasks, particularly the research proposals. It was observed from the monthly group seminars, especially in the first 3 months, that most of the students seemed to be challenged by misunderstanding or even an inadequate understanding and inappropriate applications of research designs, sampling and data collection, and analysis. Their presentations of their individual progress were indicators of such methodological issues and flaws in their research proposals. Additionally, most of the comments provided by the instructor and peers after the students' individual presentations were also noticed to be focusing on these methodological issues, such as their wrong decisions selecting certain research designs that are not aligned with their research objectives and questions. For instance, in one seminar, S3 stated in his presentation that he would carry out a study based on a qualitative research approach to answer his proposed research question: "Will the use of learners' online peer feedback impact their grades in paragraph writing?" Although the question indicates that a quantitative research approach, particularly Published by Sciedu Press 
an experimental research design, suits such a proposed study, the student selected an inappropriate research design.

The follow-up interviews also supported the above challenging issue of understanding and relating such abstract methodological concepts to students' proposals. When asked about the challenges they encountered in the course, most of the students talked about these methodological issues: "was clueless and it sounded very difficult for me to understand these research methods - I mean whether to choose quantitative, qualitative or mixed research" (S6). The instructor's voice in the interview also supported the above challenging issue among his students by stating, "You know? It's not easy to understand such methodological terminologies. Even if most of the students could understand them and differentiate among them over time, some of them seemed unable to conceptualize them and relate them to their proposals" (Instructor).

The instructor appeared challenged by the course's subject matter and how to simplify it and make it understandable for the students. When asked about the challenges he encountered in teaching the course, he pointed out: "Teaching this course is tough since it needs not only knowledge about it because this, ah you can prepare for it, but also how the teacher can make it easy for students and try to give examples" (Instructor).

\subsubsection{Task-Oriented Challenging Issues}

We also observed that some issues and flaws in students' presentations of their proposals in the seminars were related to the subject matter of their tasks or proposals. This included, for instance, the focus of their research topics for proposals, lacking rigorous problem statements, and poorly written literature reviews, including sound and relevant theories. In the follow-up interviews, most of the students talked about the challenging nature of research proposal development and even elaborated on such challenging issues by pointing out: "First, when we were asked to do the assignments, it was very difficult because the area itself is very huge and to come up with a very focused topic for the proposal in language and linguistics" (S8).

Some also referred to their confusion about what and how to start developing their proposals: "So I was feeling like when Dr. told us to make a research proposal and to choose a research topic, quite puzzled-What I am gonna do?" (S2). A few others pointed to the challenging nature of writing a critical and relevant literature review for their proposals: "For the major challenge, I think also the literature review of the proposal because I had to take a lot of others' different literature and try to relate it to the area I am studying. So, it was a big challenge because not many references for that" (S9). The instructor also confirmed what we observed and what students perceived as challenging in writing their proposals: "I would say that writing a research proposal from the title to methodology during the course is not easy because it requires your knowledge on previous research, issues, and gaps" (Instructor).

\subsubsection{Active Teaching and Learning-Oriented Challenges}

Although most of the above challenges centering on the content of the course and tasks assigned to the students appeared to be minimized through the instructor's and peer support provided and received in the various active teaching and learning activities, there were also other challenging concerns arising from engagement in active research method teaching and learning. The first concern observed from the WhatsApp group and Google Docs is related to the time-consuming and effort-demanding nature of the active teaching and learning approach. We noticed that the instructor and his students spent extra time beyond the regular class time allocated for the course in discussing and revising the drafts. Some of the students also talked about this concern in the interviews: "This way of teaching and learning seemed great, but my only concern is that I took much of our time as you know we needed to discuss outside the class" (S7). Additionally, a few of them also felt much pressure caused by their constant effort in discussing and revising their tasks, especially in the initial stage: "I felt much pressure when you started WhatsApping us because I am not good with this, but then I decided to keep it next to me as I was just afraid if I missed anything" (S1).

When asked about the challenges emerging from his active teaching of the course, the course instructor appeared to be most challenged by the effort he made in reading and commenting on students' drafts of the tasks: "I was not really concerned about the time I spent outside the class as much as I was concerned about the effort-I think you have seen such heavy work on reading and giving feedback on students' tasks" (Instructor).

Another challenge that we did not observe, but rather was articulated by the students and the course instructor in the follow-up interviews, was the students' concern about the reliability of peer support and feedback. Although most of the students appreciated the group work on the critical report task, specifically the peer feedback they exchanged, some referred to the reliability of peer feedback as one challenging concern. Therefore, when asked about any other challenges emerging from active learning of research methods, those students attempted to compare instructor and peer feedback, and even demonstrated a preference for instructor feedback as it is provided by a more knowledgeable 
source: "I think so. I just feel that my peer feedback may be wrong, so I may have that kind of doubt about it, but for the lecturer's feedback, I don't have any doubt about it" (S5).

\section{Discussion and Implications}

As summarized in Table 1, the study's findings suggest that the students reported perceived opportunities for learning afforded by the active learning approach used in the research methodology course. Consistent with previous research on active learning of research methodology (e.g., Ball \& Pelco, 2006; Barraket, 2005; Edwards \& Thatcher, 2004; Saeed \& Al Qunayeer, 2020; Vandiver \& Walsh, 2010), the findings of the present study have theoretical implications for research methodology courses. Student engagement in research-oriented tasks such as research proposals and critiques allowed them to enhance their learning about research methods. Their feedback exchanges evidenced this in the seminars and online discussions and their reflections on the course. In this regard, better learning of research methodology is not only about students acquiring knowledge about research methods; it also includes their abilities to connect what is learned to their assigned tasks. Such perceived linkage is necessary for learners to feel the relevance of research methodology courses to their research (Ball \& Pelco, 2006; Barraket, 2005; Edwards \& Thatcher, 2004; Lundahl, 2008).

Table 1. A summary of the key findings

\begin{tabular}{ll}
\hline \multicolumn{1}{c}{ Learning Opportunities } & \multicolumn{1}{c}{ Challenging Issues } \\
\hline Learning about research methodologies & Content-oriented challenging issues \\
\hline $\begin{array}{l}\text { An opportunity to enhance research } \\
\text { methodology-related tasks }\end{array}$ & Task-oriented challenging issues \\
\hline $\begin{array}{l}\text { Creating interests in students for learning } \\
\text { about research methodology }\end{array}$ & Active teaching and learning-oriented challenges \\
\hline Feeling satisfied and confident & \\
\hline
\end{tabular}

In this study, active teaching and learning of research methodology offered the opportunity for task refinement. Text refinement refers to students' attempts, with the instructor's support or feedback, to revise their tasks and enhance the quality of their final submitted tasks. This corroborates what was reported by previous studies (Vandiver \& Walsh, 2010; Braguglia \& Jackson, 2012; Keenan \& Fontaine, 2012; Saeed \& Al Qunayeer, 2020;) that the implementation of peer review in a research methodology course assisted learners in exchanging feedback and revising their texts. This is not to strongly claim that the final products submitted by students excelled the earlier drafts in all aspects rather than content and methods.

The students in this study also appreciated group work and discussions as part of the active learning approach. Specifically, the learners valued the chances for exchanging ideas, collaborating on their critical reports, learning from each other, and seeing their issues through the eyes of their peers. Likewise, some researchers (e.g., Jakeman et al., 2017; Keenan \& Fontaine, 2012) reported that students learned greatly about research methods from group discussions. This appreciation of group discussions could be due to the focus of such discussions on students' work rather than merely on the material or content of the course. Unlike what was reported by Keenan and Fontaine (2012) - that one concern about group discussions is the inability to link the content to students' projects - in this study, the students discussed their progress of the assigned tasks and linked them to the course content.

Active teaching and learning of research methodology should aim to increase learners' satisfaction with their learning and feel confident about conducting research. In this study, the students' feeling of satisfaction was derived from their realization of the role of the course in meeting their expected goal-learning about research methodology and applying it to their research proposals. This feeling is important since it is an indicator that the teaching and learning activities did not deviate from the learning outcomes of the course the students expected (Lundahl, 2008). In this study, all learners except S4 and S5 expressed their positive views on the role of active teaching and learning in developing their self-confidence by comparing themselves when they enjoyed the course and after finishing it. Learners' feelings of self-confidence are an important outcome of active teaching and learning of research methodology (Barraket, 2005; Jakeman et al., 2017). Otherwise, their lack of self-confidence is one of the major hindrances in learning about research methods (Kilburn et al., 2014). This is also partially consistent with Saeed and Al Qunayeer (2020), who reported that implementation of the active learning approach allowed postgraduates to enhance their learning experience about research methodology, increase their familiarity with the different research methods, and cause them to feel more self-confident.

The main contribution of this study is not about the identification of the major challenging issues and concerns 
arising from teaching and learning of research methodology. However, it is about the comprehensive view of these challenges, categorized into course/subject matter, task, and active teaching and learning. The students were challenged to understand methodological terminologies for the subject matter-oriented challenges and successfully apply them to their assignments. This is not new, given that several studies (Crooks et al., 2010; Keenan \& Fontaine, 2012; Hesse-Biber, 2015; Nind \& Lewthwaite, 2018; Saeed et al., 2020) pointed to the complex and abstract nature of the contents of research methodology courses. However, what is of relative importance here is that even instructors are challenged by such abstract knowledge of research methodology and how to make this knowledge easy and applicable for learners. This is what was Nind and Lewthwaite (2018) referred to as pedagogic knowledge - how to teach research methodology courses to students and deal with various emerging issues and challenges.

Our findings indicate that the students were also challenged by the tasks themselves - the content or their knowledge about research areas on the topics of their research interests. Research-related tasks such proposals tend to be challenging for students because it requires them to gain sufficient knowledge about the research topic, what has been done so far, what major issues have been identified, and what is missing in the literature review that needs to be investigated. Although students may overcome such challenges over time with more reading of earlier research and instructional support, they are more likely to face other challenges in writing and synthesizing the literature reviews for their proposals.

Despite the positive views on active teaching and learning of research methodology, this approach has its limitations and imposes challenging concerns on students and instructors. Engaging in active teaching and learning involved much time and effort on the part of students and course instructors outside the classroom time. Although this extended time facilitated through technological tools was intended to overcome the issue of time limitations highlighted in earlier research (Lundahl, 2008; Coronel Llamas \& Boza, 2011; Keenan \& Fontaine, 2012 ; Engbers, 2016), it placed heavy work and pressure on the students and the course instructor (Ball \& Pelco, 2006; Lundahl, 2008; Saeed \& Al Qunayeer, 2020). Therefore, we suggest scheduling the online activities beyond the classroom time in a few prescribed hours a week rather than any time. Another challenging issue arising from involving learners in peer feedback on research methodology learning is whether students rely on and trust their peer feedback on complicated methodological issues and flaws. This needs the instructor's support by commenting on peer feedback to confirm their points or suggestions.

In this study, our findings illustrated that teaching research methodology posed several challenges for the course instructor. Therefore, we suggest that the course be taught by two expert instructors, or even a group of instructors. In other words, while one instructor is an expert in quantitative approaches, other instructors can be interested in qualitative approaches. This also means that the classes will not be delivered by one instructor but by the entire group of instructors, thus taking into account their interests, knowledge, and expertise in research methodology. By so doing, the challenges one instructor encounters will be minimized. This will also minimize the pressure on one instructor generated from his effort in monitoring and providing feedback on students' research methodology-related tasks. Having more than one instructor for the course will allow each instructor to mentor only some students rather than all students from the start of their assignments to the final stage of submission. Assigning students instructors should be done according to the instructor's interests in research methodology and his knowledge about the subject matter of students' focus of assignments.

\section{Conclusion}

The present study aimed to explore the reflections of a group of undergraduates and the course instructor on the active teaching and learning of a research methodology at Majmaah university. The findings demonstrated that the way the course was taught afforded the undergraduates opportunities for better learning about research methodology and enabled them to enhance their assigned tasks, create interest in research through group discussions, develop their self-confidence, and become satisfied with their learning. On the other hand, the undergraduates and the course instructor were challenged by the abstract knowledge of the course, the tasks assigned to the undergraduates, and the active teaching and learning approach itself. The study provided pedagogical implications for instructors and researchers in research methodology courses.

Despite the encouraging findings of the study, this study has several limitations. First, the number of students was small, which may affect the generalization of the findings to other contexts. Therefore, such findings need to be treated with caution by future researchers. Another limitation is that the findings reported in the study were based on a thematic analysis of our observations and follow-up interviews. Although our observations helped us take notes on the most challenging issues the students and the course instructor faced, such challenges could have been better 
supported from a textual analysis of students' drafts of tasks. Therefore, future research should focus on students' drafts to provide a thorough analysis of such challenging issues in research methodology. Future studies could also video-record teaching and learning practices in research methodology courses to provide enriching insights into the challenges in such courses from theoretical and pedagogical perspectives.

\section{References}

Ball, C. T., \& Pelco, L. E. (2006). Teaching research methods to undergraduate psychology students using an active cooperative learning approach. International Journal of Teaching and Learning in Higher Education, 17(2), 147-154. Retrieved from https://www.isetl.org/ijtlhe/

Barraket, J. (2005). Teaching research method using a student-centred approach? Critical reflections on practice. Journal of University Teaching and Learning Practice, 2(2), 64-74. Retrieved from https://files.eric.ed.gov/fulltext/EJ1059434.pdf

Benson, A., \& Blackman, D. (2003). Can research methods ever be interesting? Active Learning in Higher Education, 4(1), 39-55. https://doi.org/10.1177/1469787403004001004

Braguglia, K. H., \& Jackson, K. A. (2012). Teaching research methodology using a project-based three course sequence critical reflections on practice. American Journal of Business Education, 5(3), 347-352. https://doi.org/10.19030/ajbe.v5i3.7007

Coronel Llamas, J. M., \& Boza, A. (2011). Teaching research methods for doctoral students in education: Learning to enquire in the university. International Journal of Social Research Methodology, 14(1), 77-90. https://doi.org/10.1080/13645579.2010.492136

Crooks, V. A., Castleden, H., \& Tromp-van Meerveld, I. (2010). Teaching research methods courses in human geography: Critical reflections. Journal of Geography in Higher Education, 34(2), 155-171. https://doi.org/10.1080/03098260903093646

Drew, V., \& Mackie, L. (2011). Extending the constructs of active learning: implications for teachers' pedagogy and practice. The Curriculum Journal, 22(4), 451-467. https://doi.org/10.1080/09585176.2011.627204

Earley, M. A. (2014). A synthesis of the literature on research methods education. Teaching in Higher Education, 19(3), 242-253. https://doi.org/10.1080/13562517.2013.860105

Edwards, D. F., \& Thatcher, J. (2004). A student-centred tutor-led approach to teaching research methods. Journal of Further and Higher Education, 28(2), 195-206. https://doi.org/10.1080/0309877042000206750

Engbers, T. A. (2016). Comparative research: An approach to teaching research methods in political science and public administration. Teaching Public Administration, 34(3), 270-283. https://doi.org/10.1177/0144739416640850

Gunn, A. (2017). Critical debates in teaching research methods in the social sciences. Teaching Public Administration, 35(3), 241-259. https://doi.org/10.1177/0144739417708837

Hesse-Biber, S. (2015). Mixed methods research: The "thing-ness" problem. Qualitative Health Research, 25(6), 775-788. https://doi.org/10.1177/1049732315580558

Howard, C., \& Brady, M. (2015). Teaching social research methods after the critical turn: Challenges and benefits of a constructivist pedagogy. International Journal of Social Research Methodology, 18(5), 511-525. https://doi.org/10.1080/13645579.2015.1062625

Jakeman, R. C., Henderson, M. M., \& Howard, L. C. (2017). Reflective pedagogy: The integration of methodology and subject-matter content in a graduate-level course. Teaching in Higher Education, 22(2), 207-221. https://doi.org/10.1080/13562517.2016.1237494

Keenan, K., \& Fontaine, D. (2012). Listening to our students: Understanding how they learn research methods in geography. Journal of Geography, 111(6), 224-235. https://doi.org/10.1080/00221341.2011.653651

Keyser, M. (2000). Active learning and cooperative learning: understanding the difference and using both styles effectively. Research Strategies, 17(1), 35-44. https://doi.org/10.1016/S0734-3310(00)00022-7

Kilburn, D., Nind, M., \& Wiles, R. (2014). Learning as researchers and teachers: The development of a pedagogical culture for social science research methods? British Journal of Educational Studies, 62(2), 191-207. https://doi.org/10.1080/00071005.2014.918576

Leshem, S., \& Trafford, V. N. (2006). Stories as mirrors: Reflective practice in teaching and learning. Reflective 
Practice, 7(1), 9-27. https://doi.org/10.1080/14623940500489567

Lombard, B. J. J., \& Kloppers, M. (2015). Undergraduate student teachers' views and experiences of a compulsory course in research methods. South African Journal of Education, 35(1), 1-14. https://doi.org/10.15700/201503070032

Lundahl, B. W. (2008). Teaching research methodology through active learning. Journal of Teaching in Social Work, 28(1-2), 273-288. https://doi.org/10.1080/08841230802179373

Nind, M., \& Lewthwaite, S. (2018). Methods that teach: Developing pedagogic research methods, developing pedagogy. International Journal of Research \& Method in Education, 41(4), 398-410. https://doi.org/10.1080/1743727X.2018.1427057

Nind, M., Kilburn, D., \& Luff, R. (2015). The teaching and learning of social research methods: Developments in pedagogical knowledge. International Journal of Social Research Methodology, 18(5), 455-461. https://doi.org/10.1080/13645579.2015.1062631

Roman, T. A., \& Uttamchandani, S. (2018). Researching pedagogy within small active learning classrooms: Examining enacted pedagogies of learner and instructor interactions. International Journal of Research \& Method in Education, 41(4), 1-21. https://doi.org/10.1080/1743727X.2018.1452199

Saeed, M. A., Al-Ahdal, A. A. M. H., \& Al Qunayeer, H. S. (2020). Integrating research proposal writing into a postgraduate research method course: What does it tell us? International Journal of Research \& Method in Education, 44(3), 303-318. https://doi.org/10.1080/1743727X.2020.1777963

Schoch, K. (2016). Case study research. In G. J. Burkholder, K. A. Cox, \& L. M. Crawford (Eds.), The scholar-practitioner's guide to research design (1st ed., pp. 5886-6283). Laureate Publishing.

Seawright, J., \& Gerring, J. (2008). Case selection techniques in case study research: A menu of qualitative and quantitative options. Political Research Quarterly, 61(2), 294-308. https://doi.org/10.1177/1065912907313077

Tashakkori, A., \& Teddlie, C. (2003). Issues and dilemmas in teaching research methods courses in social and behavioural sciences: US perspective. International Journal of Social Research Methodology, 6(1), 61-77. https://doi.org/10.1080/13645570305055

Vandiver, D. M., \& Walsh, J. A. (2010). Assessing autonomous learning in research methods courses: Implementing the student-driven research project. Active Learning in Higher Education, 11(1), 31-42.

https://doi.org/10.1177/1469787409355877

\section{Copyrights}

Copyright for this article is retained by the author(s), with first publication rights granted to the journal.

This is an open-access article distributed under the terms and conditions of the Creative Commons Attribution license (http://creativecommons.org/licenses/by/4.0/). 